\title{
A PROSPECTIVE STUDY OF COMPARISON OF RIPASA AND ALVARADO SCORES FOR THE DIAGNOSIS OF ACUTE APPENDICITIS IN GOVERNMENT VELLORE MEDICAL COLLEGE
}

\author{
Loganathan Devarajan1, Ramesh A2, Gayathri $S^{3}$
}

${ }_{1}^{1}$ Associate Professor, Department of General Surgery, Government Vellore Medical College, Vellore, Tamilnadu, India. ${ }^{2}$ Assistant Professor, Department of General Surgery, Government Vellore Medical College, Vellore, Tamilnadu, India. 3Junior Resident, Department of General Surgery, Government Vellore Medical College, Vellore, Tamilnadu, India.

ABSTRACT

\section{BACKGROUND}

Acute appendicitis is a common clinical emergency presenting as acute abdominal pain. The presenting symptoms of appendicitis quite often overlap with other causes of acute abdomen making it difficult to make a correct diagnosis at an early stage of presentation. The diagnostic dilemma is further compounded by the fact that the classic clinical symptoms may not be present in about half of the cases. Improved diagnostic accuracy not only helps in taking early management decisions but also curtails negative appendectomy rates. One of the common scoring systems is Alvarado system ${ }^{(1)}$ which is based on clinical and laboratory investigations of acute appendicitis. It includes pain migration to RIF, anorexia, nausea and vomiting, tenderness, rebound tenderness, fever, leukocytosis and shift of WBC to the left. Another scoring system RIPASA score has been in use in Asian countries that takes into consideration for age, sex, urine analysis, guarding, Rovsing sign, Asian origin in addition to the variables in Alvarado score. We wanted to compare Alvarado and RIPASA scoring systems.

\section{METHODS}

This is a comparative study (2) of two scores in the diagnosis of acute appendicitis involving 250 patients admitted in our hospital for a period of one year from July 2017 to August 2018.

\section{RESULTS}

- $\quad$ RIPASA scoring system is more sensitive (98.42\%) as compared to the Alvarado scoring system (73.7\%).

- $\quad$ RIPASA score is more specific (90\%) as compared to Alvarado scoring system (80\%).

- $\quad$ PPV of RIPASA scoring system is $99.46 \%$ as compared to $94.32 \%$ of the Alvarado scoring system.

- $\quad$ NPV of the RIPASA scoring system is $75 \%$ while that of Alvarado scoring system is $3.38 \%$.

\section{CONCLUSIONS}

Both Alvarado and RIPASA scoring systems have significant differences when Non-Parametric Pearson Chi Square Test was applied with a $p$ value of $<0.05$; correlation between the Alvarado (3) and RIPASA Score rho $=0.538$ and $p$ value $<0.05$; significant difference was found with positive agreement between the two scores. From the above parameters we conclude that RIPASA Score is a better Scoring system in diagnosing cases of acute appendicitis(4) as compared to the Alvarado score (5).

HOW TO CITE THIS ARTICLE: Devarajan L, Ramesh A, Gayathri S. A prospective study of comparison of RIPASA and Alvarado scores for the diagnosis of acute appendicitis in government Vellore medical college. J. Evolution Med. Dent. Sci. 2019;8(19):15781581, DOI: $10.14260 /$ jemds/2019/349

\section{BACKGROUND}

The Raja Isteri Pengiran Anak Saleha Appendicitis (RIPASA) score is a new diagnostic scoring system for the diagnosis of acute appendicitis and has been shown to have significantly higher sensitivity, specificity and diagnostic accuracy than that reported for the Alvarado or Modified Alvarado scores.

The RIPASA score is more extensive than the Alvarado score. It includes parameters such as age, gender and duration of symptoms prior to presentation, which have been shown to affect the sensitivity and specificity of the Alvarado and Modified Alvarado scores. The RIPASA score consists of

'Financial or Other Competing Interest': None.

Submission 25-02-2019, Peer Review 04-04-2019,

Acceptance 11-04-2019, Published 13-05-2019.

Corresponding Author:

Dr.Loganathan Devarajan,

Associate Professor,

Department of General Surgery,

Government Vellore Medical College,

Vellore, Tamilnadu, India.

E-mail:loganstanley63@gmail.com

DOI: $10.14260 /$ jemds $/ 2019 / 349$
14 fixed generalised parameters, with an additional parameter that is specific to our local population. We prospectively compared the RIPASA score (6) with the Alvarado score by applying both scores to patients who presented to our Department of General surgery with right iliac fossa (RIF) pain and who were suspected of acute appendicitis.

\section{METHODS}

The present study consists of 250 patients of age group 15 to 60 years diagnosed with acute appendicitis between July 2017 TO August 2018 in Government Vellore medical college.

The Study was conducted in Department of Surgery in Government Vellore medical college, Vellore from JULY 2017 TO AUGUST 2018. Ethical committee clearance was taken for the study. This is a prospective study of all patients coming to our institution in the Department of Surgery (7) with complaints of right iliac fossa abdominal pain. The basic aim is to compare the Alvarado Score and RIPASA Score in their efficacy to diagnose acute appendicitis so that the diagnostic criteria can be improved, and we can reduce the unwanted operations and expensive imaging studies 
Type of the Study (7)

Cross - Sectional study.

\section{Statistical Analysis}

The collected data were tabulated and statistically analyzed using SPSS program (Statistical Package for Social Science) version 24. Qualitative data were represented as frequencies and relative percentages. Chi square test $(\chi 2)$ and Fisher exact was used to calculate difference between qualitative variables as indicated. Quantitative data were expressed as mean \pm SD (Standard deviation) for parametric and median and range for non-parametric data. The significance level for all above mentioned statistical tests was done P-value $\leq 0.05$ indicates significant, $\mathrm{p}<0.001$ indicates highly significant difference while, $\mathrm{P}>0.05$ indicates non-significant difference.

\begin{tabular}{|c|c|}
\hline Characteristics & Score \\
\hline M- Migration Of Pain To The Right Lower quadrant & 1 \\
\hline A- Anorexia & 1 \\
\hline N- Nausea & 1 \\
\hline T- Tenderness in The Right Lower Quadrant & 2 \\
\hline R- Rebound Tenderness & 1 \\
\hline E- Elevated Temperature & 1 \\
\hline L- Leucocytosis & 2 \\
\hline S- Shift of WBC To the Left & 1 \\
\hline Total & 10 \\
\hline Alvarado Score \\
\hline
\end{tabular}

\section{Interpretation of Alvarado Score (4)} Score Interpretation

- 1-4 Very unlikely, keep under observation.

- 5-6 Acute appendicitis may be, for regular observation.

- 7-8 Acute appendicitis is probable, operate.

- 9-10 Acute appendicitis definite, operate.

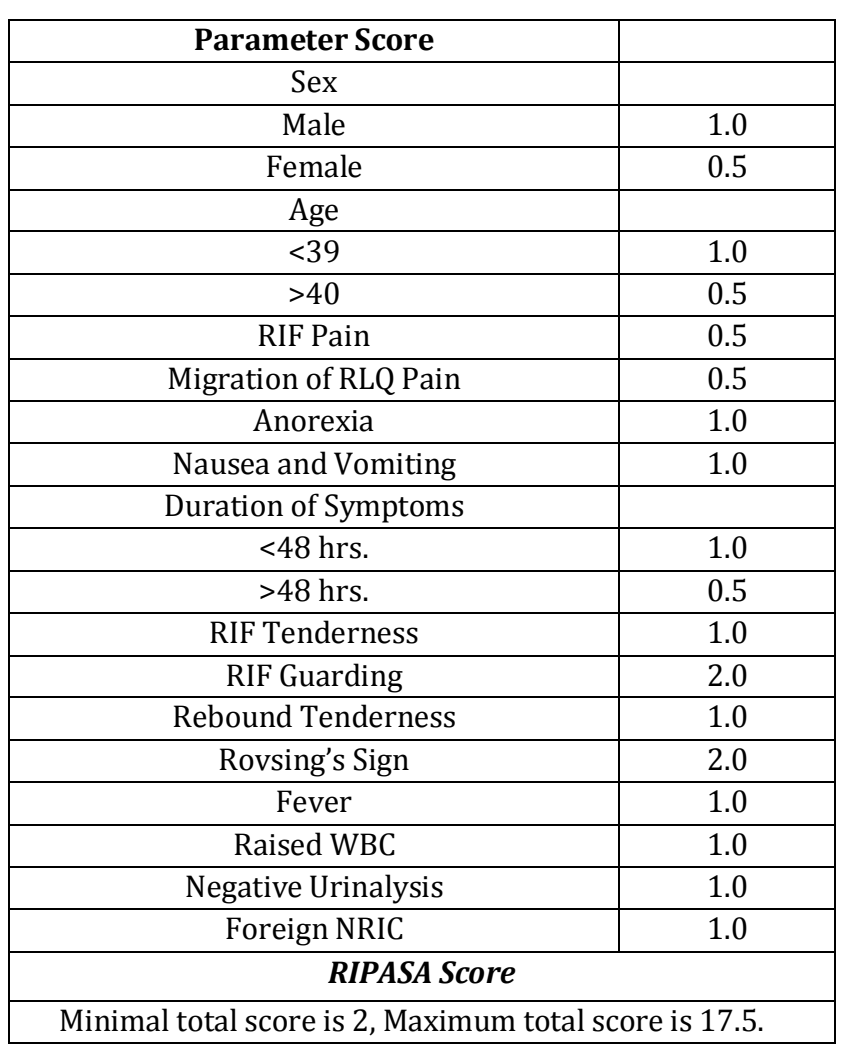

\begin{tabular}{|c|c|}
\hline $\begin{array}{c}\text { AGE Groups No. of Patients in Particular Age } \\
\text { Group }\end{array}$ & \\
\hline $15-25$ & $115(45 \%)$ \\
\hline $26-35$ & $65(26.5 \%)$ \\
\hline $36-45$ & $45(18.5 \%)$ \\
\hline $46-60$ & $25(10 \%)$ \\
\hline Table 1. Age Group \\
\hline
\end{tabular}

\begin{tabular}{|c|c|c|}
\hline & Number & Percentage \\
\hline Male & 165 & $66 \%$ \\
\hline Female & 85 & $34 \%$ \\
\hline \multicolumn{3}{|c|}{ Table 2. Male: Female Ratio } \\
\hline Out of 250 patients 165 are Males and 85 are Females. \\
\hline
\end{tabular}

\begin{tabular}{|c|c|c|}
\hline Signs and Symptoms & & \\
\hline Pain in Abdomen & 243 & $97.5 \%$ \\
\hline Nausea and Vomiting & 220 & $88 \%$ \\
\hline Anorexia & 195 & $78 \%$ \\
\hline Fever & 165 & $66 \%$ \\
\hline RIF Tenderness & 190 & $86 \%$ \\
\hline Rebound Tenderness & 75 & $30 \%$ \\
\hline Guarding & 85 & $34 \%$ \\
\hline Rovsing Sign & 80 & $32 \%$ \\
\hline \multicolumn{2}{|c|}{ Signs and Symptoms } \\
\hline
\end{tabular}

\begin{tabular}{|c|c|}
\hline Histopathology & No. of Patients \\
\hline Positive (+ve) & 237 \\
\hline Negative (-ve) & 13 \\
\hline \multicolumn{2}{|c|}{ Post-Operative Histopathology of Appendix } \\
\hline
\end{tabular}

\begin{tabular}{|c|c|}
\hline Treatment Modality & No. of Patients \\
\hline Emergency Appendicectomy & 241 \\
\hline Exploratory Laparotomy & 9 \\
\hline \multicolumn{2}{|c|}{ Treatment Modality } \\
\hline
\end{tabular}

\begin{tabular}{|c|c|c|c|}
\hline Variables & RIPASA $>$ 7.5 & Alvarado $>7.0$ & p Value \\
\hline Sensitivity & $98.42 \%$ & $73.7 \%$ & $<0.0001$ \\
\hline Specificity & $90 \%$ & $80 \%$ & $<0.0001$ \\
\hline $\begin{array}{c}\text { Positive } \\
\text { Predictive Value }\end{array}$ & $99.46 \%$ & $94.32 \%$ & $<0.0001$ \\
\hline $\begin{array}{c}\text { Negative } \\
\text { Predictive Value }\end{array}$ & $75 \%$ & $3.38 \%$ & $<0.0001$ \\
\hline
\end{tabular}

Comparison Between the RIPASA and Alvarado Scoring Systems with Respect to Different Variables

\section{RESULTS}

- The study period was 12 months with total 250 patients were involved. Total 250 patients of age range 15 to 60 years of age. Peak age group was 15 to 25 years of age (45\%). Least affected age group was above 45 years of age.

- $\quad$ Males are predominantly affected with M: F ratio 1.9: 1.

- Most common presentation was found Pain in abdomen in $97.5 \%$ of patients followed by Nausea and Vomiting in $88 \%$ and Right Iliac Fossa Tenderness (9) in $86 \%$ of the patients. Majority of patients (58\%) presenting after 48 hours of the onset of symptoms to the hospital.

- $\quad$ WBC counts were found to be raised $\left(>10,000 / \mathrm{mm}^{3}\right)$ in $56 \%$ of the patients.

- In $94 \%$ of the patients Urine culture and sensitivity was found positive. 
- $\quad$ Almost $90 \%$ of the patients were diagnosed positive for acute appendicitis on Ultrasonography. In Histopathology, $95 \%$ of the patients tested positive for acute appendicitis.

- Emergency Appendicectomy were performed in about 193 (96.5\%) patients and 190 (95\%) patients confirmed Histology for acute appendicitis.

- Mean Hospital stay was 3.05 days.

- Wound infection was found in $2.5 \%$ of the patients, $2 \%$ having Wound Gaping and $2 \%$ had Postoperative adhesions.

- $\quad$ Most of the patients (65\%) were discharged within 4 days of admission.

- $\quad$ Regarding Alvarado Score and RIPASA Score, out of 250 patients 135(54\%) patients had Alvarado Score $<7$ and $115(46 \%)$ had score $>=7$

- And $4(1.5 \%)$ Patients had RIPASA Score $<5$,

- $52(6 \%)$ patients have scores between 5-7,

- $166(66.5 \%)$ patients had scores between 7.5-11.5,

- $69(27.6 \%)$ patients had scores $>=12$.

\section{DISCUSSION}

The present study included clinically suspected 250 cases of appendicitis, with age group of patients taken from 15 to 60 years of age. There were 165 males and 85 females in the study.

All the patients clinically suspected to have acute appendicitis were scored according to both the scoring systems and were taken up for surgery.

Histopathology was considered the gold standard for the confirmation of the diagnosis. The histopathologically inflamed appendix was classified acute appendicitis. The histopathologically normal appendix was put under no appendicitis group. The symptoms such as RIF pain was present in 243 patients $(97.5 \%)$ in the study group. anorexia was present in 195 patients (78\%), nausea and vomiting were present in 220 patients (73\%), fever was present in 165 patients $(66 \%)$ and presenting with duration of symptoms less than 48 hours were 105(42\%). Of all the symptoms RIF pain, Pain migration, nausea and vomiting and duration of symptoms came out to be statistically significant (with $\mathrm{p}$ value $0.032,0.048,0.016$ and 0.042 respectively) but RIF pain and nausea and vomiting came out to be highly significant (with $\mathrm{p}$ value 0.032 and 0.016 respectively)Signs such as RIF tenderness was present in 190 cases ( $p$ value 0.016), guarding was present in 85 ( $p$ value 0.226 ), rebound tenderness was present in 75 (p value 0.461 ) and Rovsing`s sign was present in 80 ( $p$ value 0.134 ). Out of all the clinical signs, RIF tenderness was found to be statistically significant. Alvarado score when applied in all patients clinically suspected to have appendicitis, had 115 cases (46\%) with a score of $\geq 7$ and 135 cases (54\%) with a score of $<7$. On analysing with respect to the histopathology, the sensitivity and specificity of the scoring system in the present study came out to be $70 \%$ and $20 \%$ respectively. The positive and negative predictive values were $94.32 \%$ and $3.38 \%$ respectively. Accuracy was $74 \%$ with 8 false positive cases and 57 false negative cases. Khan et al applied the Alvarado scoring system in Asian population and achieved a sensitivity and specificity of $59 \%$ and $23 \%$ respectively, with a positive predictive value of $83.3 \%$ with negative appendicectomy rate of $15.6 \%$. RIPASA score when applied in all the patients clinically suspected of having appendicitis, had 235 patients (94\%) in $\geq 7.5$ group and 15 patients $(6 \%)$ in $<7.5$ score group. When analysed with respect to histopathology the sensitivity of the scoring system in the present study came to be $98.42 \%$, specificity of $90 \%$, positive and negative predictive values of $99.46 \%$ and $75 \%$ respectively-

- On comparing both the scoring systems in the present study, RIPASA score has been found to be more sensitive (98.42\%) as compared to Alvarado score (73.7\%).

- RIPASA score is also more specific (90\%) as compared to Alvarado score (80\%).

- Positive and negative predictive values of RIPASA came out to $99.46 \%$ and $75 \%$ as compared to Alvarado having $94.32 \%$ and $3.38 \%$. Accuracy of the RIPASA score was $97 \%$ as compared to the Alvarado score having accuracy of $74 \%$. In a prospective study by Chon $\mathrm{CF}$ et al, the sensitivity, specificity, positive predictive value, negative predictive value and diagnostic accuracy of the RIPASA score were 98\%, 81.3\%, 85.3\%, 97.4\% and 91.8\% respectively when compared to Alvarado score with sensitivity, specificity, positive predictive value, negative predictive value and diagnostic accuracy of $68.3 \%$, $87.9 \%, 86.3 \%, 71.4 \%$ and $86.5 \%$ respectively.

\section{CONCLUSIONS}

Both Alvarado and RIPASA scoring systems have significant differences when Non-Parametric Pearson Chi Square Test was applied with a $p$ value of $<0.05$; correlation between the Alvarado (3) and RIPASA Score rho $=0.538$ and $p$ value $<0.05$; significant difference was found with positive agreement between the two scores. From the above parameters we conclude that RIPASA Score is a better Scoring system in diagnosing cases of acute appendicitis ${ }^{(4)}$ as compared to the Alvarado score (5).

\section{REFERENCES}

[1] Chong CF, Adi MI, Thien A, et al. Development of the RIPASA score: a new appendicitis scoring system for the diagnosis of acute appendicitis. Singapore Med J 2010;51(3):220-5.

[2] Livingston EH, Woodward WA, Sarosi GA, et al. Disconnect between incidence of nonperforated and perforated appendicitis: implications for pathophysiology and management. Ann Surg 2007;245(6):886-92.

[3] Chong CF, Thien A, Mackie AJA, et al. Evaluation of the RIPASA score: a new appendicitis scoring system for the diagnosis of acute appendicitis. Brunei Int Med J 2010;6(1):17-26.

[4] Pal KM, Khan A. Appendicitis: a continuing challenge. J Pak Med Assoc 1998;48(7):189-92.

[5] Khan I, Ur Rehman A. Application of alvarado scoring system in diagnosis of acute appendicitis. J Ayub Med Coll Abbottabad 2005;17(3):41-4.

[6] Wani MM, Yousaf MN, Khan MA, et al. Usefulness of the Alvarado scoring system with respect to age, sex and time of presentation, with regression analysis of individual parameters. Internet J Surg 2007;11(2):1-5.

[7] Alvarado A. A practical score for the early diagnosis of acute appendicitis. Ann Emerg Med 1986;15(5):55764. 


\section{Jemds.com}

[8] Andersson M, Andersson RE. The appendicitis inflammatory response score: a tool for the diagnosis of acute appendicitis that outperforms the Alvarado score. World J Surg 2008;32(8):1843-9.
Original Research Article

[9] Al-Hashemy AM, Seleem MI. Appraisal of the modified Alvarado Score for acute appendicitis in adults. Saudi Med J 2004;25(9):1229-31. 